only has a valuable life been saved, but it has been saved by an operation most strenuously opposed.

With these constantly accumulating instances of success, it is to be hoped that the vain opposition still so earnestly waged by some against ovariotomy will soon cease; or, at least, that the operation may be allowed to hold equal favor with others whose record of results is far less favorable, yet whose legitimacy is never brought into question.

[To be continued.]

\title{
PERMANGANATE OF POTASH IN CEREBRO-SPINAL MENINGITIS.
}

By Dr. Isaad Kay, of Springhiedd, Oirto.

[Cummunicated for the Boston Mredical and Burgical Journal.]

Having seen several articles in the Boston Medical and Surgical Journal lately upon spotted fever, or, more properly, cerebro-spinal meningitis, as it prevails in and about Boston, I am prompted to contribute a few lines in regard to its appearance here in the West. During the last six months, cases of the disease, mostly in childron, have occurred in various parts of Ohio, Indiana and Illinois, and although the symptoms seem to have been essentially the same everywhere, yet the malady has been variously named by the people and physicians of the different localities in which it has made its appearance. Malignant scarlet ferer, spotted fever, and cerebro-spinal meningitis, especially the latter two names, have generally been applied to it. In some neighborhoods it has carried consternation equal to that which formerly attended the visitations of cholera.

About the first of January last, this city was visited by what we now consider to be this discase, in the family of a Mr. D., whose daughter, aged 18 years, and son, aged 10 years, were attacked with violent fever and evident congestion of the nervous centres, and both died after an illness of about three days. They were both corpses in the house at the same time.

Jan. 10th, Mr. A., bridge-builder, a large, healthy, athletic man, was taken with a slight chill, soon followed with fever and pain in head and neck. In less than six hours delirium set in, which required an attendant or two to keep him in bed. This excitement in forty-eight hours subsided into a quieter form, such as low muttering and expression of strange fancies. His decubitus was on the back, with head somewhat thrown back, and the oppression of the nervous centres was such as to give him at times but little respira. tory power, the tongue falling back into the throat so as to make it necessary betimes to change his position on his side. Pulse generally over 120 . After treatment of the usual antiphlogistic character, he died, four days after the attack.

In a day or two after this case terminated, two of Mr. W.'s chilVoL. Lxx.-No. 19* 
dren, of this city, were attacked with what I consider the same disease, both dying in less than forty-eight hours.

Shortly after the death of these two cascs, Mr. Williams's fanily, of this place, was invaded, and in about one month five of his children, all under 13 years of age, died, one after the other, with intervals of one, two, four, seven, eight, and ten days.

During the progress of the last mentioned cases, the child of $\mathrm{Mr}$. $D$. died suddenly, and a post-mortem examination of the case was made, conducted mainly by Dr. Dunlap, of this city. This examination revealed an excessively engorged state of the meninges of the cerebellum, medulla oblongata, and cervical portion of the medulla spinalis. The appearance of theso parts was such as confirm the pathologists who have named the disease cercbro-spinal meningitis.

One peculiar symptom in most of these cases among children, is the great rapidity of the respirations, sometimes ranging from cighty to one hundred and ten per minute. In most of the cases which have come under my observation; especially of children, the patient would lie with the head thrown back as far as possible, and nothing would induce them to bring it forward, until the case began to improve. Otherwise this position would be maintained until death. In regard to the management of these cases, I will merely observe that the whole catalogue of antiphlogistics, and tonics, and various preparations of chlorine, were used, without, as I think, any beneficial result. That the treatment used was incffectual to a rery distressing degree, may be appreciated when I state that out of the first twenty cases in this city and vicinity, only one recorered, and that, too, with deafness and other serious impairment of the system. In the case which recovered, copper-colored spots about the size of a split pea made their appearance on the second day, and remained on the body for nearly two weeks. These spots in many cases did not become very distinct until after death. But they were so often absent altogether, as to make the name of spotted fever quite objectionable in point of truth.

After these first twenty cases had occurred in and about Springfield, and terminated as stated, I was called to see $\mathrm{Mr}$. George Johnson, aged 22 years, and a member of the 44th Ohio Voluntecr Infantry, who was scized with a strange and to him unusual sense of oppression in the head. In a few minutes after the onset of these feelings, he fell senseless upon the floor and had to be carried to bed, where he remained for thirty-six hours, most of the time so wildly delirious as to require several persons to kecp him in bed. In a few hours after he was carried to the bed, the lungs began to labor under unmistakable symptoms of intense congestion. Breathing was very difficult, and large quantities of very bloody mucus were thrown up by a hurried cough and spasmodic cmesis. At the suggestion of Dr. Dunlap, who was called upon to see the case with me, the patient was given the solution of permanganate of potash, one grain to the 
ounce of rain watcr, of which solution one tablespoonful every hour was given. The vomiting ccased almost immediately, and the brain, in less than one hour, was considerably relieved of congestion, and the patient, after lying for three days in a partially delirious state, began very rapidly to recover, and in five days could walk about the city. Permanganate of potash, in the dose above mentioned, every hour, with occasional doses of opium to quiet the delirium, and an application of cold, wet cloths to the occiput and over the cervical vertclire, constituted the only treatment.

The next case in which this treatment was used, was that of Milton Cole, aged 18 years. He was attacked with a slight chill and darting pains through the brain, which in a few hours rendered him quite delirious. The pain finally settled into the back part of the brain, and in the region of the cervical medulla spinalis, drawing the head back upon the neck. Pulse 130 per minute, and delirium almost equal to mania a potu. Numcrous efforts were made to vomit, but little was thrown up. During the first two days there were cramps of the legs and constant changing of position in the bed, and from the bed to the chair, and a desire to go ont of doors. A homoopathist was called in to see him on the first day, and pronounced it "typhoid fever of the brain," and said that he would undoubtedly die. Immediately upon seeing him next day, I commenced giving him the solution of permanganate of potash every hour, alternating with half a grain of opium until the patient was quicted, after which the solution was continued alone until the delirium required the nervous sedative. This treatment alone was pursued for one week, when all the unpleasant symptoms left him, and a rapid convalescence followed.

Since the adoption of this treatment here, the statistics show that over three fourths of the cases have recovered. One thing we observed particularly in regard to these cases, viz., a great intolerance of purgatives. On account of this intolerance, we deemed it better to let the patient go for three or even four days without a movement of the bowels, rather than resort to cathartics. No harm seemed to result from this course, and, notwithstanding the large quantities of opium used, we found one tablespoonful of castor oil sufficient in all cases to move the bowels. Castor oil, with a small quantity of turpentine, was given frequently after convalescence had set in, to clean off the tongue, which was generally covered in the centre with a heavy hrownish coat, with red glazed edges.

These crude and imperfect notes and remarks are thrown out to the profession for what they may be worth, and with the vicw of eliciting still further observations on a disease which is causing some panic in various parts of our country. 